\title{
Taxonomy of the genus Amphiareus (Heteroptera: Anthocoridae) in Southeast Asia
}

\author{
KAZUTAKA YAMADA \\ Tokushima Prefectural Museum, Bunka-no-mori Park, Hachiman-chô, 770-8070 Tokushima, Japan; \\ e-mail: yamada-kazutaka-1@mt.tokushima-ec.ed.jp
}

Key words. Heteroptera, Anthocoridae, Amphiareus, new species, Southeast Asia, taxonomy

\begin{abstract}
Four species of the genus Amphiareus are recognized in southeastern Asia, including two new species, A. edentulus and $A$. rompinus, both from Johor, Malaysia. The two known species, A. constrictus (Stål) and A. ruficollaris Yamada \& Hirowatari are also diagnosed and figured; the latter is recorded from this region for the first time. The genus is diagnosed and briefly discussed.
\end{abstract}

\section{INTRODUCTION}

The flower bug genus Amphiareus Distant of the tribe Dufouriellini is represented by one cosmopolitan and four Palearctic species (Yamada \& Hirowatari, 2003). Among the latter, A. obscuriceps (Poppius, 1909) was recently recorded from North America (Henry et al., 2008). The cosmopolitan species, A. constrictus (Stål, 1860), is distributed mainly in the Old and New World tropics and subtropics. In turn, Palearctic species are inhabitants of temperate to cold temperate areas, except for a single subtropical species, A. ochraceus Yamada \& Hirowatari, 2003, that is restricted to the Ryukyus, Japan. Though Amphiareus is widely distributed in the world, its fauna in the tropical region, such as southeastern Asia, has been lightly studied. Only $A$. constrictus was known to occur in this region to date (Distant, 1910; Péricart, 1996). Three species of this genus have been recognized through the recent continuing investigations of the author and colleagues.

In this paper, Amphiareus of southeastern Asia is revised. Two new species, $A$. edentulus and $A$. rompinus, are described below, and the two previously known species are diagnosed based on the specimens from southeastern Asia. The genus is diagnosed, supplementary illustrations included and briefly discussed for distinguishing characters.

\section{MATERIAL AND METHODS}

Most specimens were preserved in $80 \%$ ethyl alcohol, then dried and mounted for study. Other specimens examined are housed in several other institutions. Examination and illustration of the genitalia and other detailed external structures, such as the metathoracic scent gland, were made from specimens macerated in 5\% hot $\mathrm{KOH}$ solution for 3-5 min. They were dissected with micro-pins in glycerin on a well-glass slide under a Nikon Stereoscopic Zoom Microscope SMZ1500 binocular microscope. Illustrations were made with this microscope, and with the aid of an eyepiece grid. Photographs presented in this paper were taken using a Hirox digital microscope KH-7700. All measurements are given in millimeters.
Depositories of the types and the other specimens are abbreviated as follows: HNHM - Hungarian Natural History Museum, Budapest, Hungary; NSMT - National Science Museum, Tokyo, Japan; TKPM - Tokushima Prefectural Museum, Tokushima, Japan. The new distributional records for the known species are indicated by an asterisk $\left(^{*}\right)$ after the name of a region. Abbreviations are also used for several collectors as follows: KY (Kazutaka Yamada); MT (Masaaki Tomokuni); TI (Tadashi Ishikawa)

\section{Amphiareus Distant}

Poronotus Reuter, 1871: 561 (junior homonym of Poronotus Gill, 1861, Pisces). Type species: Xylocoris constrictus Stål, 1860, subsequent designation by Kirkaldy (1906: 120).

Amphiareus Distant, 1904 (September): 220. Type species: Xylocoris fulvescens Walker, 1872 (= Xylocoris constrictus Stål, 1860); original designation.

Poronotellus Kirkaldy, 1904 (November): 280. New replacement name for Poronotus Reuter, 1871 (synonymized by Herring, 1965: 203).

Diagnosis. Easily distinguished from other genera of the tribe Dufouriellini by the following characters: oblong ovate body principally yellowish to brownish colored; head produced anteriorly, about as long as width across eyes; rostrum nearly reaching middle of mesosternum; pronotum narrowed anteriorly, with distinct collar and swollen callus; apical portion of corium about as wide as embolium; membrane usually with three veins; ostiolar peritreme almost straight, connected to angulate carina and extending to anterior margin of metapleura; metasternum with bifurcate projection at middle of posterior margin; scissures on abdominal tergite reaching posterior margin of segment II. Yamada \& Hirowatari (2003) provided further diagnostic characters.

Remarks. Morphological characters for accurately distinguishing the species in Amphiareus as are stated below: (1) color; (2) length of antennal segment II to head width across eyes ratio; (3) shape of pronotum; (4) length and density of setae on head, pronotum and hemelytra; (5) shape of ostiolar peritreme; (6) shape of pygophore and paramere. 


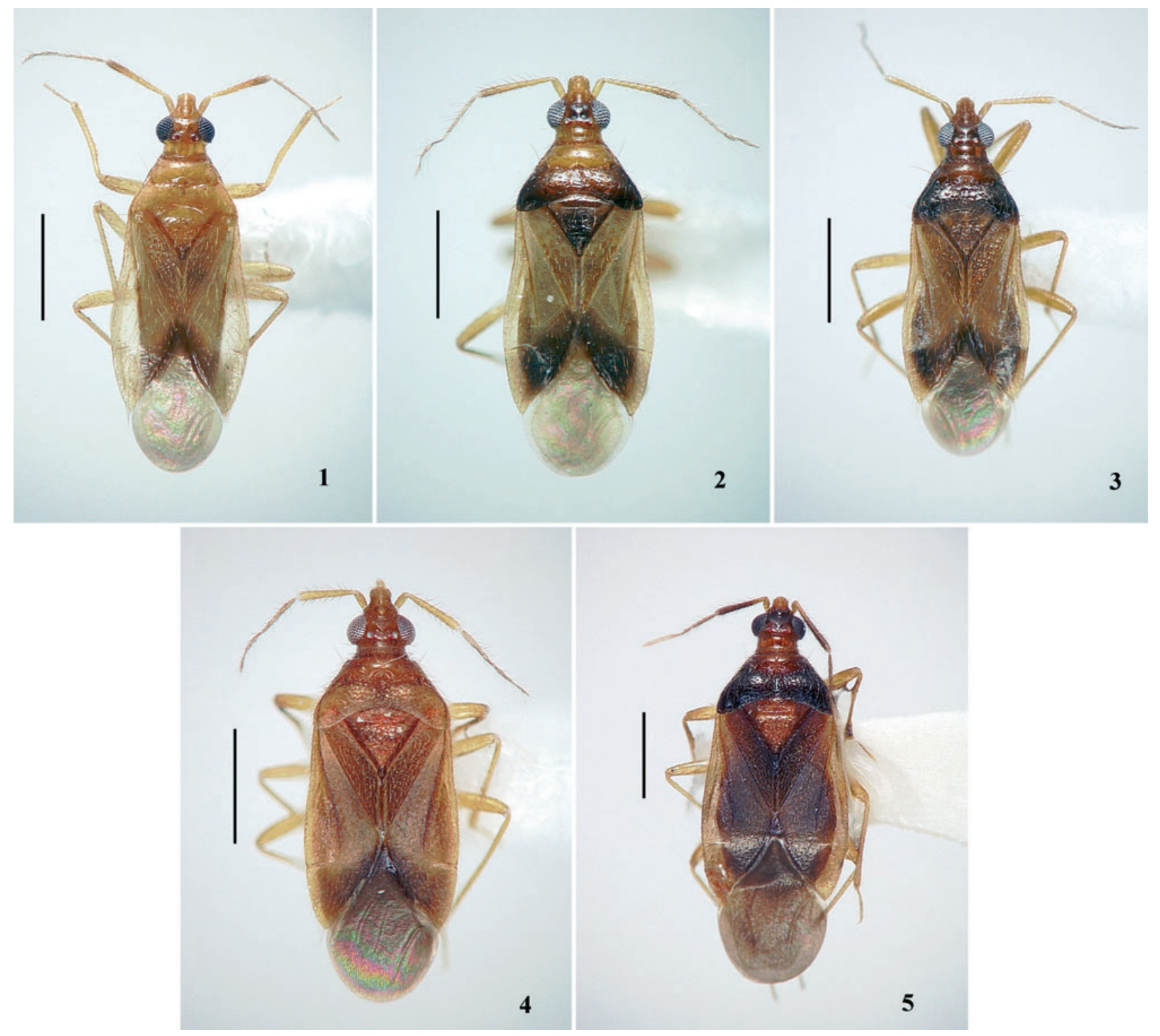

Figs 1-5. Amphiareus spp. 1 -A. constrictus, ô, Thailand; 2 - ditto, ô, Malaysia; 3 - A. edentulus sp. n., ô, Malaysia (holotype); $4-$ A. rompinus sp. n., ô, Malaysia (holotype); 5 -A. ruficollaris, ठิ, Vietnam. Scales: $0.5 \mathrm{~mm}$.

Further, the number and position of teeth on the male fore tibia may be useful in distinguishing the species. Geographical variation may occur in the number of teeth on male fore tibia. The male genitalia is indispensable for reliable identification of the species, as the female lacks useful genital organs such as copulatory tube and omphalus for species separation.

In the key to Japanese species of Amphiareus presented by Yamada \& Hirowatari (2003: 291), the present new species, $A$. edentulus sp. n. and $A$. rompinus sp. n., will key to couplets 2 and 3 respectively, with $A$. ochraceus as well as $A$. ruficollaris and $A$. obscuriceps. Therefore, the key (2nd and 3rd couplets) is revised as follows:

2a Body uniformly brown to reddish brown, densely covered with setae; antenna uniformly pale yellow; apical part of corium narrowly dark brown. ............ 2b
- Body shining yellowish brown, sparsely covered with long setae; antenna pale yellow with apex or apical half of second segment dark brown; apical part of corium and cuneus broadly dark brown. . . . . . . . . . . . . 4

$2 \mathrm{~b}$ Antennal segment II about 1.2 times as long as head width across eyes; ostiolar peritreme nearly straight and not bent

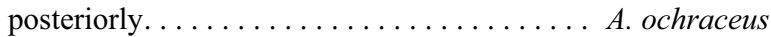

- Antennal segment II about 0.9 times as long as head width across eyes; ostiolar peritreme slightly bent posteriorly. .... $\ldots \ldots \ldots \ldots \ldots \ldots \ldots$. . rompinus $\mathrm{sp} . \mathrm{n}$.

3a Postocular region, collar, and callus red to reddish brown... ........................... A. ruficollaris

- Postocular region and pronotum uniformly dark brown to reddish brown. .................... $3 b$

3b Male fore tibia with a row of teeth on ventral surface; hemelytra mostly light brown to brown........ A. obscuriceps

- Male fore tibia lacking a row of teeth on ventral surface; hemelytra yellowish brown with the clavus, apical part of corium, and cuneus widely dark brown. . A. edentulus sp. n. 

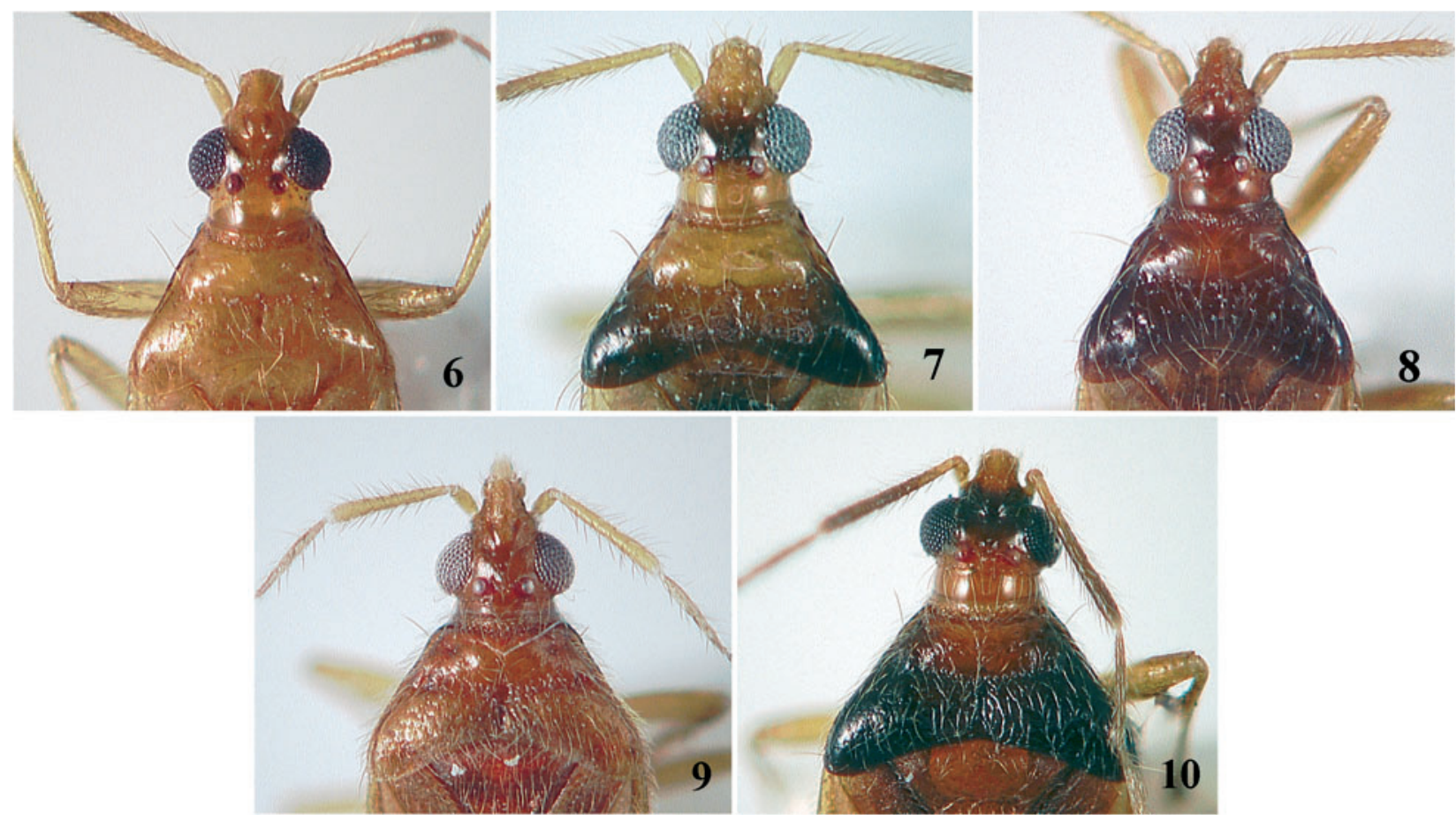

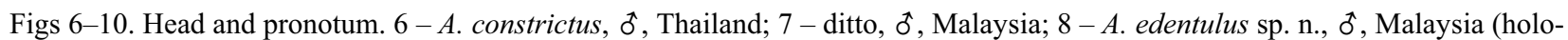

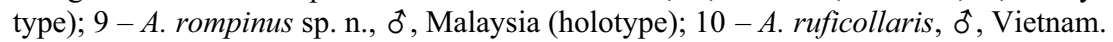

Biology. The species of this genus in southeastern Asia seem to inhabit principally dead plant materials, and are found in various types of dead leaf clusters of the upper part of evergreen trees, on the ground, dead drooping banana leaves, and sometimes dead ferns, where they were collected along with tiny arthropods. These microenvironments in southeastern Asia are characterized by high temperatures and humidity, providing preferable environments, and a variety of prey for Amphiareus and other anthocorid bugs (cf. Mockford, 1993; Lattin, 1999; Henry et al., 2008). The occurrence of Amphiareus species in such habitats was more common than the other genera of Dufouriellini (e.g. Buchananiella, Cardiastethus, Physopleurella).

\section{Amphiareus constrictus (Stål)}

(Figs 1, 2, 6, 7, 17)

Xylocoris constrictus Stål, 1860: 44. Holotype: ô, Rio de Janeiro, Brazil; Naturhistoriska Riksmuseet, Stockholm.

See Yamada \& Hirowatari (2003) for a detailed synonymy.

Diagnosis. Recognized by the body (Figs 1,2) that is generally shining yellowish brown, sparsely covered with silky, long, reclining setae, the antennal segment II about 1.2 times as long as head width across eyes, the ostiolar peritreme evenly straight laterad, blunt apically, the male fore tibia (Fig. 17) curved outwards at middle, bearing 15-17 teeth on midventral surface, and the paramere long, weakly curved, gradually tapered toward apex in dorsal view.

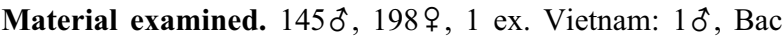
Me, 170 m alt., Ha Giang, 20.v.1998, MT (NSMT); 3 ô, 4 ㅇ, Bo Lu, Ba Be, 140 m alt., Cao Bang, 13.v.1998, MT (NSMT); 1 \%, 4ㅇ, Ba Be, 230 m alt., Cao Bang, 11.-12.v.1998, MT (NSMT);
10ิ, Lao Cai, 400 m alt., Coc Xan, 27.xi.1971, Topàl-Matskási (HNHM); 10, 1ㅇ, Ba Be Lake, Ba Be, Bac Kan, 3.v.2006, B.W. Lee (TKPM); $3 \hat{\sigma}$, Don Den, Ba Be, Bac Kan, 4.v.2006, B.W. Lee (TKPM); $1 \hat{\delta}, 4 \uparrow$, Thinh Hung, $150 \mathrm{~m}$ alt., Yen Bai, 30.ix.1995, MT (NSMT); 19, Xuan Dinh, NW of Hanoi, 26.iv.1966, Topàl (HNHM); 1 9 , Mai Lam, NE of Hanoi, 30.i.1986, Mahunka-Oláh (HNHM); 1 ㅇ, Tam Dao, 950 m alt., Vinh Phuc, 21.ix.1995, MT (NSMT), 2ㅇ, 17.vi.1997, MT (NSMT), 2q, 2.vii.1997, MT (NSMT); 10 , Me Linh Station of

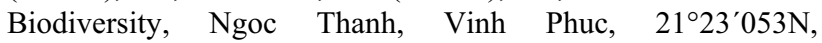
105²'453E, $65 \mathrm{~m}$ alt., 28.-29.viii.2007, TI (TKPM); 19 , nr. Phu Ly, Tuong Linh, Ha Nam, 25.v.1966, Topàl (HNHM); 1 ㅇ, Cuc Phuong, Ninh Binh, 13.v.1966, Topàl (HNHM); 19 , Cuc Phuong, $170 \mathrm{~m}$ alt., Gia Vien, Ninh Binh, 10.vii.1997, MT (NSMT), 20, 11.vii.1997, light trap, MT (NSMT); 1, Cau Cau, Thanh An, Nghe An, 18 $43^{\prime} 303 \mathrm{~N}, 105^{\circ} 17^{\prime} 003 \mathrm{E}, 40 \mathrm{~m}$ alt., 9.viii.2007, TI (TKPM); 1 के, 1 \% , Phong Nha-Ke Bang National

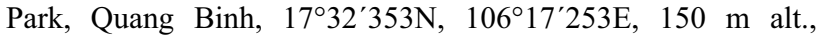
12.viii.2007, TI (TKPM); 5 $0^{2}, 8$, Thon Loan Ly, Lang Co, Thua Thien Hue, $16^{\circ} 14^{\prime} 503 \mathrm{~N}, 108^{\circ} 04^{\prime} 253 \mathrm{E}, 5 \mathrm{~m}$ alt., 15.viii.2007, light trap, TI (TKPM); 2 \%, Phu An, Tan Phu, Dong Nai, 29.xii.2001, TI (TKPM). Thailand: $1 \delta^{\hat{\alpha}}$, Pakhia, 1500 $\mathrm{m}$ alt., Chiang Dao, Chiang Mai, 4.-6.v.2000, S. Nagashima (TKPM), 1 ô, 1 ㅇ, 6.-8.v.2002, TI (TKPM); 1 ô, 3 ㅇ, Mae La Nong, $400 \mathrm{~m}$ alt., Phrao, Chiang Mai, 8.viii.2001, TI \& S. Nagashima (TKPM); 10,1 , Nong Hoi, 970 1000 m alt., Mae Rim, Chiang Mai, 6.viii.2001, TI (TKPM), 1 ô, 18.viii.2001, TI (TKPM); 3 \%, Mae Sa, 400 450 m alt., Mae Rim, Chiang Mai, 1.-3.viii.2001, TI (TKPM), $60 \hat{0}, 5$ q, 18.viii.2001, light trap, TI $\&$ S. Nagashima (TKPM), 22 $\sigma^{\star}$ (one shown in Figs 1, 6), 12의, 15.-17.v.2002, TI (TKPM); 1 \% , Pang Klang, 1000 1200 m alt., Doi Mae Tho, Chiang Mai, 7.viii.2001, TI (TKPM); 23 $\widehat{0}, 46$, Chiang Khian, 800 900 m alt., Doi Suthep, Chiang Mai, 14.-15.viii.2001, TI (TKPM); 10 , 1 오, Mae Choe, Uttaradit, 17 45'N, 100 101'E, Y. Nakatani (no collected date) (TKPM). Malaysia: 1q, Cameron Highlands, Tanah Rata, Pahang, 28.ii.2003, S. Nagashima (TKPM); $150^{\widehat{t}}$ (one shown in Figs 2, 

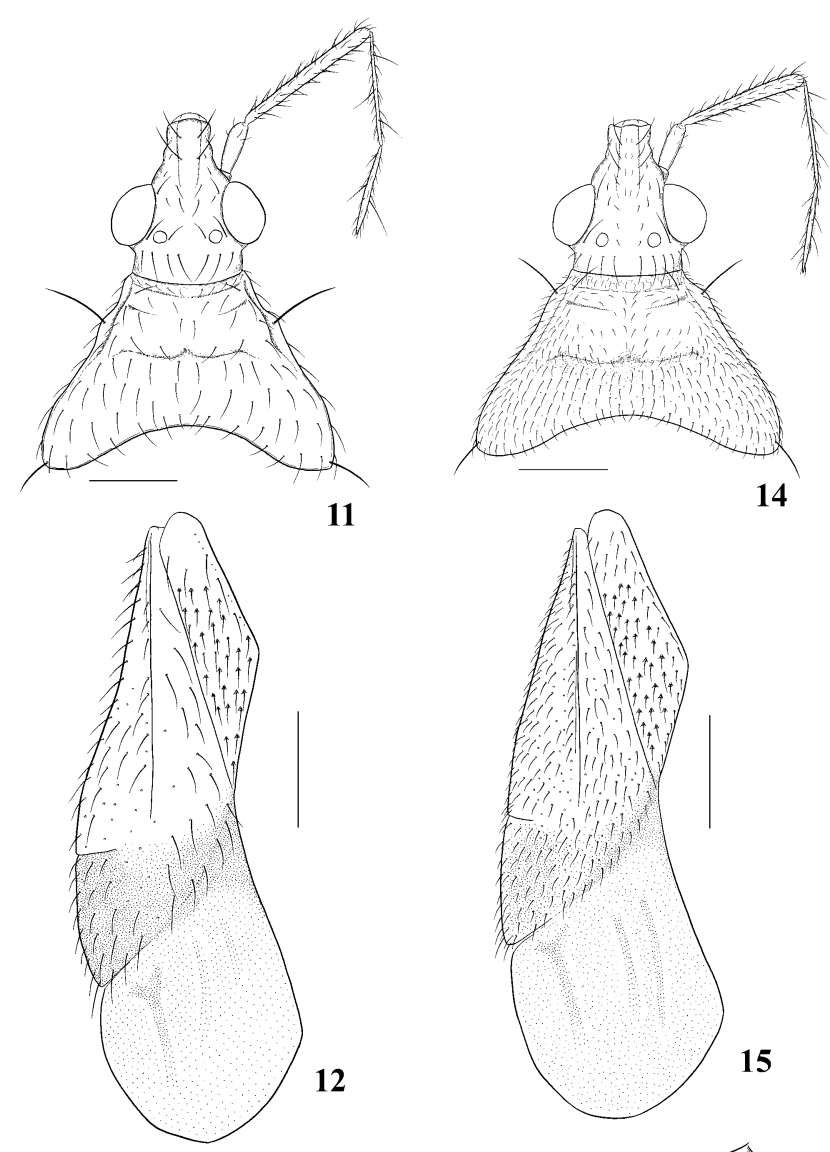

15
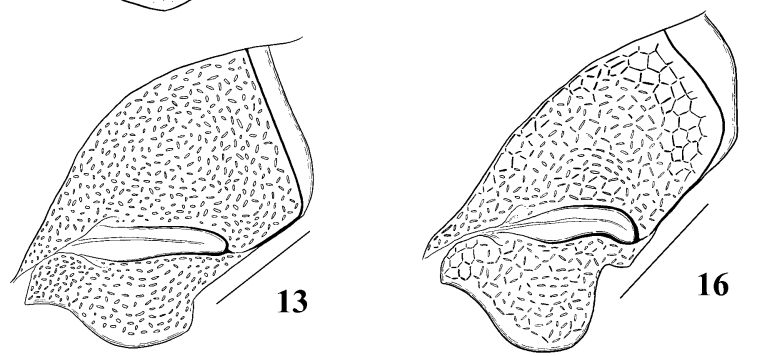

Figs 11-16. Amphiareus edentulus sp. n. (11-13) and A. rompinus sp. n. (14-16). 11, 14 - head and pronotum; 12, 15 left fore wing; 13, 16 - ostiolar peritreme and evaporative area. Scales: $0.3 \mathrm{~mm}$ for 12,$15 ; 0.2 \mathrm{~mm}$ for 11,$14 ; 0.1 \mathrm{~mm}$ for 13 , 16.

7, 17), 12ㅇ, Ulu Gombak, Selangor, 7.-10.v.2005, KY (TKPM), 3 ô, 16요, 8.-10.v.2005, light trap, KY (TKPM); 19 , near Endau-Rompin, Pahang, 12.v.2005, light trap, KY (TKPM); 1 ex., Kampung Juara, Pulau Tioman, Pahang, 9.-17.iii.1995, O. Merki (abdomen broken) (HNHM); 8ठ, 13 ㅇ, Kampung Peta, Endau-Rompin, Johor, 14.-18.v.2005, KY (TKPM), 50ิ, 3 ๆ, 13.-16.v.2005, KY (TKPM). Philippines: 20, 1 \% , Mt. Maquiling, $400 \mathrm{~m}$ alt., Luzon Is., 12.ix.1985, MT (NSMT); 5 ㅇ, upper Barakatan, $1100 \mathrm{~m}$ alt., Apo range, Mindanao Is., 4.-5.viii.1985, MT (NSMT). Indonesia: $20 \hat{0}, 19$, Buring, Malang, Java Is., 07 $59^{\prime} 40.03 \sim 42.03 \mathrm{~S}$, $112^{\circ} 39^{\prime} 38.03 \sim 39.13 \mathrm{E}, \quad 513 \sim 518 \mathrm{~m}$ alt., 24.viii.2005, TI (TKPM); 10, Wono-koyo, Malang, Java Is., $07^{\circ} 49^{\prime} 50.63 \sim 64.23 \mathrm{~S}, 112^{\circ} 34^{\prime} 20.83 \sim 36.43 \mathrm{E}, 1137 \sim 1162 \mathrm{~m}$ alt.,

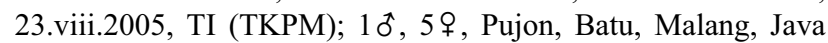
Is., $07^{\circ} 51^{\prime} 02.83 \sim 08.43 \mathrm{~S}, 112^{\circ} 26^{\prime} 15.63 \sim 16.13 \mathrm{E}, 968 \sim 982 \mathrm{~m}$ alt., 22.viii.2005, TI (TKPM); $3 \delta^{\star}, 1$ \%, Kalibaru, Banyuwangi, Java Is., $08^{\circ} 18^{\prime} 07.63 \sim 22.23 \mathrm{~S}, 114^{\circ} 00^{\prime} 10.53 \sim 17.73 \mathrm{E}, 390 \sim 490$ m alt., 26.viii.2005, TI (TKPM); $2 \hat{0}$, Pura Belatung, Buleleng, Bali Is., $08^{\circ} 10^{\prime} 11.83 \sim 20.43 \mathrm{~S}, 114^{\circ} 40^{\prime} 57.53 \sim 41^{\prime} 00.63 \mathrm{E}, 84 \sim 110$ $\mathrm{m}$ alt., 30.viii.2005, TI (TKPM); 40, 2 \% , Pura Luhur, Muncak Sari, Tabanan, Bali Is., $08^{\circ} 23^{\prime} 113 \mathrm{~S}, 115^{\circ} 05^{\prime} 143 \mathrm{E}, 760 \mathrm{~m}$ alt., 9.xi.2007, TI (TKPM); 5ठ, 8ㅇ, Pura Batu Salahan, Bengkel, Tabanan, Bali Is., $08^{\circ} 22^{\prime} 24.33 \sim 23^{\prime} 32.33 \mathrm{~S}, \quad 115^{\circ} 05^{\prime} 49.13$ $\sim 57.33 \mathrm{E}, 685 \sim 894 \mathrm{~m}$ alt., 3.ix.2005, TI (TKPM); 2 우 , Pura Jero Sasah, near Wangaya, Tabanan, Bali Is., S08 $22^{\prime} 01.73 \sim 15.63$, E1150' 22.93 27.23, 874 934 $\mathrm{m}$ alt., 4.ix.2005, TI (TKPM), 20ิ, 2오, 10.xi.2007, TI (TKPM); 1 오, Jatiluwih, Tabanan, Bali Is., $08^{\circ} 21^{\prime} 31.83 \sim 48.43 \mathrm{~S}, 115^{\circ} 06^{\prime} 46.73 \sim 59.23 \mathrm{E}, 874 \sim 934 \mathrm{~m}$ alt., 14.iii.2005, TI (TKPM), 4ㅇ, 13.viii.2005, TI (TKPM); 20 , 1 , Soka, Tabanan, Bali Is., $08^{\circ} 21^{\prime} 18.83 \sim 23.83 \mathrm{~S}$, $115^{\circ} 08^{\prime} 10.63 \sim 18.83 \mathrm{E}, \quad 713 \sim 752 \mathrm{~m}$ alt., 13.viii.2005, TI (TKPM); 8ᄎ, 19, Yehketipat, Buleleng, Bali Is., $08^{\circ} 14^{\prime} 09.43 \sim 17.63 \mathrm{~S}, 115^{\circ} 09^{\prime} 25.13 \sim 10^{\prime} 44.23 \mathrm{E}, 1410 \sim 1550 \mathrm{~m}$ alt., 8.iii.2005, TI (TKPM); 1 ô, 1 오, Batu Sesa, Tabanan, Bali Is., $08^{\circ} 17^{\prime} 313 \mathrm{~S}, 115^{\circ} 09^{\prime} 463 \mathrm{E}, 1250 \mathrm{~m}$ alt., 8.xi.2007, TI (TKPM); 20ิ, 6ㅇ, Candikuning, Tabanan, Bali Is., $08^{\circ} 14^{\prime} 56.43 \sim 15^{\prime} 49.63 \mathrm{~S}, 115^{\circ} 10^{\prime} 00.03 \sim 56.13 \mathrm{E}, 1260 \sim 1290 \mathrm{~m}$ alt., 9.iii.2005, TI (TKPM); 1 \%, Krang Bedil, Mataram, Lombok Is., 4.iii.2005, TI (TKPM); 1 , Bajawa, Ngada, Flores Is., $08^{\circ} 48^{\prime} 15.43 \mathrm{~S}, 120^{\circ} 57^{\prime} 19.33 \mathrm{E}, 1154 \mathrm{~m}$ alt., 27.viii.2006, TI (TKPM); $30^{\circ}, 1$ 으, Nualise, Ende, Flores Is., $08^{\circ} 45^{\prime} 39.83 \mathrm{~S}$, $121^{\circ} 52^{\prime} 04.63 \mathrm{E}, 580 \mathrm{~m}$ alt., 22.viii.2006, TI (TKPM).

Distribution. Vietnam*, Thailand (Nakatani, 2004; present study), Myanmar (Distant, 1906), Malaysia (Distant, 1910; present study), Singapore (Poppius, 1909), Philippines*, Indonesia (Distant, 1910; present study); Pan-temperate and pan-tropical zones. This species is widely distributed in southeastern Asia, but detailed country records have been fragmented. Vietnam and Philippines are new country record for the species.

Remarks. The specimens from southeastern Asia are divisible into two color patterns: (1) head, pronotum, scutellum uniformly yellowish brown, rostrum uniformly pale yellow, hemelytra yellowish brown with apical part of corium and inner half of cuneus widely dark brown, venter of thorax uniformly yellowish brown (Figs 1, 6); (2) head yellowish brown, vertex dark brown, rostral segment II with dark brown tinge, pronotum yellowish brown with posterior half or posterior angles dark brown, scutellum dark brown, hemelytra yellowish brown to brown with apical part of corium and whole of cuneus widely dark brown, posterior half of prosternum and whole of mesosternum dark brown (Figs 2, 7). The specimens of these two types were frequently collected simultaneously and at similar frequences from many localities and various habitats.

Among specimens with coloration type (1) there are sometimes a few specimens that superficially resemble $A$. morimotoi (Hiura, 1958). They may differ from $A$. mori$m o t o i$ by the eye not sexually dimorphic (in $A$. morimotoi, larger in males than in females), the antennal segment II about 1.2 times as long as head width across eyes (vs. as long as head width across eyes), and ostiolar peritreme evenly straight and blunt at apex (vs. rounded posterior margin and apically connecting to carina).

\section{Amphiareus edentulus, sp. $\mathbf{n}$.}

(Figs 3, 8, 11-13, 18, 21-23)

Diagnosis. Recognized by generally brown to dark brown body (Fig. 3), sparsely covered with yellow, long 
setae, dorsum shiny, hemelytra (Fig. 3) yellowish brown with clavus, apical part of corium, and cuneus broadly dark brown; antennal segment II (Figs 3, 11) about 1.1 times as long as head width across eyes; male fore tibia (Fig. 18) lacking a row of teeth on ventral surface, paramere (Fig. 21) curved along left margin of pygophore and approaching anterior margin of pygophore.

Description. Coloration. Body (Fig. 3) generally brown to dark brown. Head (Figs 3, 8) reddish brown with vertex with fuscous tinge; margin of ocelli red. Antennae and rostrum uniformly pale yellow. Pronotum (Figs 3, 8) dark brown to reddish brown; callus somewhat paler than posterior half. Scutellum (Fig. 3) dark brown, same color with posterior half of pronotum. Hemelytra (Fig. 3) yellowish brown; clavus, apical part of corium, and cuneus widely dark brown; membrane smoky dark ochre, somewhat paler behind apex of cuneus. Legs pale yellow; fore tibia tinged basally with dark brown. Venter of thorax and abdomen blackish brown, partly reddish.

Structure. Head (Figs 3, 8, 11) shiny, smooth, sparsely covered with yellow, long, erect setae intermixed with suberect setae; head excluding neck 0.88 times as long as width across eyes; ante-ocular region 0.88 times as long as length of eye in dorsal view; vertex about 1.3 times as wide as eye in dorsal view; postocular region slightly constricted; neck distinct; eye moderately large, prominent, exceeding level of ventral surface of head in lateral view, sparsely covered with very short setae. Antennal segment I (Figs 3, 8, 11) just reaching apex of head, with short setae around apex; segment II (Figs 3, 8, 11) about 1.1 times as long as head width across eyes, slightly thickened toward apex, sparsely covered with erect setae intermixed with suberect setae, each seta slightly longer than width of segment; segments III and IV (Figs 3, 11) subequal in length, 0.73 times as long as segment II, covered with long erect setae intermixed with short reclining setae; longest seta much longer than twice width of segment; segment IV (Figs 3, 11) weakly flattened. Rostrum sparsely clothed with silky, short setae; segment III about 1.8 times as long as segment IV; segment IV about twice as long as segment II.

Pronotum (Figs 3, 8, 11) shiny, smooth, with long, stout, erect setae at one-third of lateral margin and posterolateral corner, sparsely covered with yellow, short, reclining setae; collar with a row of short setae; anterior margin slightly curved inwardly, $0.77-0.79$ times as long as mesal length; lateral margin sinuate, distinctly carinate on anterior half; posterior margin deeply curved inwardly, about 2.3 times as wide as anterior margin; callus scattered setae, with stout, erect setae and shallow depression near anterior angle, demarcated posteriorly by transverse, sinuate impression with furrows. Scutellum (Fig. 3) sparsely covered with yellow, long, reclining setae, without two foveae at middle. Hemelytra (Figs 3, 12) sparsely covered with yellow, long, reclining setae; costal margin slightly constricted basally; most setal bases on clavus distinctly raised trilobed; embolial margin longer than twice length of cuneal margin; membrane with one distinct outermost vein and two invisible inner veins, out-

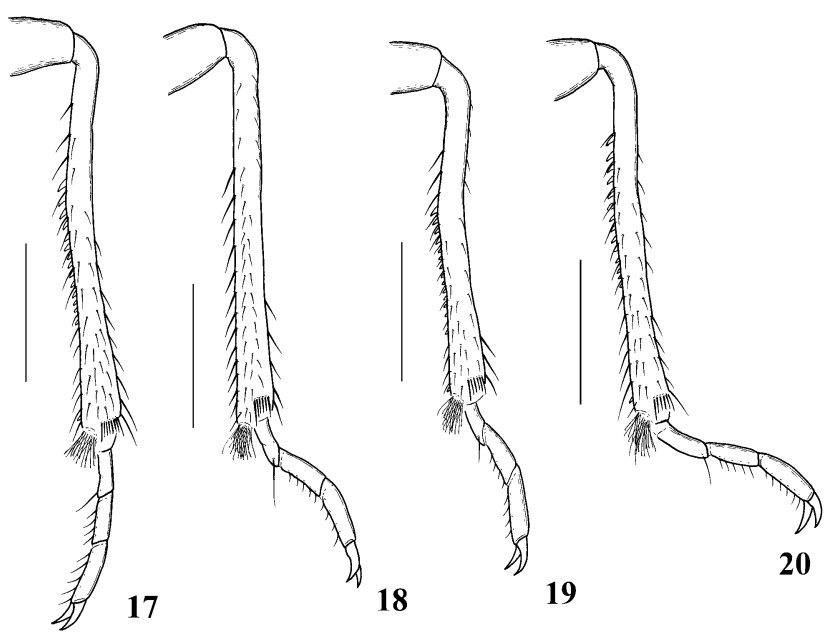

Figs 17-20. Male fore tibia and tarsus. $17-$ A. constrictus, Malaysia; $18-A$. edentulus sp. n., Malaysia; $19-A$. rompinus sp. n., Malaysia; $20-A$. ruficollaris, Thailand. Scales: $0.2 \mathrm{~mm}$.

ermost vein bifurcated basally, inner veins remote from outermost vein. Ostiolar peritreme (Fig. 13) evenly straight laterad, most similar to that of A. constrictus; carina touching lateral margin of metapleura. Legs slender, densely covered with yellow, long, suberect setae; male fore tibia (Fig. 18) straight, lacking row of teeth on ventral surface; each tibia bearing several slender spines.

Abdomen densely covered with yellow, short, reclining setae. Pygophore (Fig. 21) strongly asymmetrical in dorsal view, posteroventrally covered with two long, stout setae intermixed with short and medium length setae; paramere (Figs 21-23) very long, nearly straight, curved along left margin of pygophore, approaching the anterior margin of the pygophore; groove running along paramere broad, entirely visible from left posterolateral aspect.

Measurements. [ $0(\mathrm{n}=6) / 9(\mathrm{n}=7)$, holotype in parentheses]. Body length 2.21-2.33/2.29-2.51 (2.29); head length (excl. neck) $0.31-0.32 / 0.31-0.34(0.32)$; head width across eyes $0.34-0.37 / 0.36-0.39$ (0.36); vertex width $0.13-0.15 / 0.16-0.17$ (0.15); width between ocelli 0.07-0.09/0.09-0.11 (0.09); length of antennal segments I-IV: $0.11-0.12 / 0.11-0.12 \quad(0.12)$, $0.39-0.42 / 0.39-0.42 \quad(0.41), \quad 0.28-0.31 / 0.29-0.30 \quad(0.30)$, $0.29-0.32 / 0.29-0.31(0.29)$; length of rostral segments II-IV: $0.08-0.11 / 0.11-0.12 \quad(0.11), \quad 0.33-0.36 / 0.34-0.39 \quad(0.35)$, $0.19-0.22 / 0.20-0.22 \quad(0.19) ; \quad$ anterior pronotal width $0.27-0.28 / 0.28-0.30 \quad(0.28)$; mesal pronotal length $0.33-0.36 / 0.36-0.39 \quad(0.36)$; basal pronotal width $0.64-0.67 / 0.68-0.74 \quad(0.65)$; length of embolial margin $0.74-0.78 / 0.79-0.85(0.74)$; length of cuneal margin $0.34-0.38 / 0.40-0.43(0.36)$; maximum width across hemelytra $0.78-0.79 / 0.84-0.85(0.79)$.

Type material. Holotype $\hat{\delta}$ : (TKPM-IN-12766; Figs 3, 8, 11, 21), labelled "MALAYSIA, Johor, Endau-Rompin, Kampung Peta, 18.v.2005, K. Yamada leg.”. Paratypes: 20 (one shown in Figs 12, 13, 22, 23), $3 q$, same data as holotype; 30 (one shown in Fig. 18), 4 \%, 14.v.2005, same locality and collector as holotype. All in TKPM.

Etymology. From Latin edentulus (= no teeth, toothless), referring to the male fore tibia lacking a row of teeth on ventral surface; an adjective.

Distribution. Malaysia (Johor). 

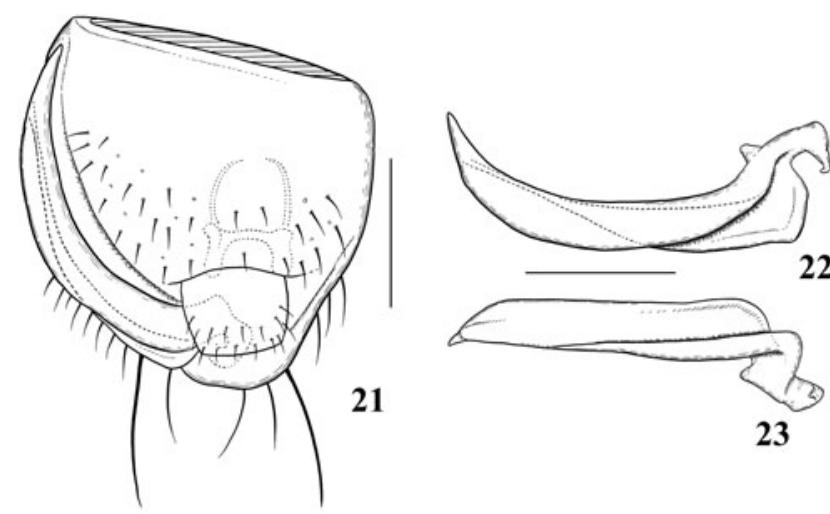

21

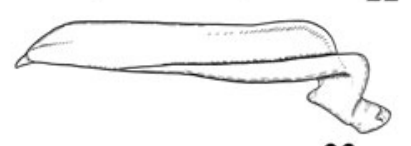

23
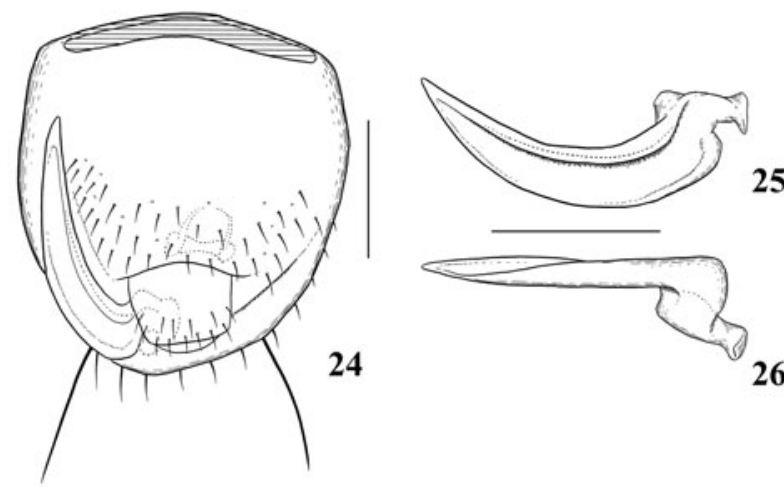

Figs 21-26. Pygophore and paramere, dorsal $(21,22,24,25)$ and posterolateral $(23,26)$ views. $21-23-A$. edentulus sp. n.; 24-26-A. rompinus sp. n. 21, 24 - holotype; 22, 23, 25, $26-$ paratype. Scales: $0.1 \mathrm{~mm}$.

Remarks. Amphiareus edentulus sp. n. is closely related to $A$. constrictus in general habitus and the shape of ostiolar peritreme; it can be distinguished by the straight fore tibia of the male and the lack of a row of teeth on ventral surface (in $A$. constrictus, curved outwards at middle, with 15-17 teeth on midventral surface), the apex of paramere approaching the anterior margin of the pygophore (vs. much remote from anterior margin). The coloration of pronotum of the new species is also similar to that of $A$. obscuriceps. However, it is separated from $A$. obscuriceps by the base of fore tibia tinged with dark brown (in A. obscuriceps, uniformly pale yellow), hemelytra yellowish brown with clavus, apical part of corium, and cuneus widely dark brown (vs. mostly light brown to brown), and the paramere very long, nearly straight, curved along left margin of pygophore (vs. moderately curved, not along left margin of pygophore).

\section{Amphiareus rompinus, sp. $\mathbf{n}$.}

(Figs 4, 9, 14-16, 19, 24-26)

Diagnosis. Readily recognized by generally reddish brown body (Fig. 4), pronotum (Figs 4, 14) densely covered with yellow, short, reclining setae and minute punctures, callus (Figs 4, 9, 14) demarcated posteriorly by transverse wide depression with dense punctures, ostiolar peritreme (Fig. 16) slightly bent posteriad, the paramere (Figs 24-26) short, weakly curved, with broad groove running along its length.
Description. Coloration. Body (Fig. 4) generally reddish brown. Head and pronotum (Figs 4, 9) uniformly reddish brown; margin of the ocelli red. Antennae and rostrum pale yellow; antennal segments III and IV tinged with dark brown; rostral segment II dark brown. Scutellum (Fig. 4) more reddish than pronotum. Hemelytra (Fig. 4) largely reddish brown; clavus and apical part of corium tinged with dark brown; membrane smoky dark ochre, basally blackish. Legs pale yellow; fore tibia basally tinged with dark brown. Venter of thorax brown to reddish brown. Ostiolar peritreme and evaporative area slightly reddish.

Structure. Head (Figs 4, 9, 14) shiny, covered with short, yellow, reclining setae intermixed with long erect setae, densely punctured on dorsal surface; head excluding neck 0.86 times as long as width across eyes; ante-ocular region 0.88 times as long as length of eye in dorsal view; vertex about 1.5 times as wide as eye in dorsal view; postocular region slightly constricted; neck distinct; eye moderately large, prominent, slightly exceeding level of ventral surface of head in lateral view, covered with very short setae. Antennal segment I (Figs $4,9,14)$ just reaching apex of head, with short setae around apex; segment II (Figs 4, 9, 14) about 0.9 times as long as head width across eyes, slightly thickened toward apex, sparsely covered with erect setae intermixed with suberect setae, each seta slightly longer than width of segment; segments III and IV (Figs 4, 14) subequal in length, about 0.8 times as long as segment II, covered with long, erect setae intermixed with short, reclining setae; longest setae much longer than twice width of segment; segment IV (Figs 4, 14) weakly flattened. Rostrum sparsely furnished with silky, short setae; segment III longer than 1.6 times length of segment IV; segment IV about twice as long as segment II.

Pronotum (Figs 4, 9, 14) with long, stout, erect setae at anterolateral and posterolateral angles, densely covered with yellow, short, reclining setae and minute punctures, posteromedially depressed; collar rugose, with row of short setae; anterior margin nearly straight, slightly shorter than mesal length; lateral margin straight, carinate on anterior half; posterior margin deeply curved inwardly, about 2.5 times as wide as anterior margin; callus shiny, with long, stout, erect setae and shallow depression near anterior angle, demarcated posteriorly by transverse, wide, sinuate depression with dense punctures. Scutellum (Fig. 4) covered with yellow, short, reclining setae, with two weak foveae at middle. Hemelytra (Figs 4, 15) uniformly covered with yellow, short, reclining setae; costal margin moderately curved; most setal bases on clavus distinctly raised trilobed; embolial margin about twice as long as cuneal margin; membrane with three veins, outermost vein distinct and bifurcated basally, inner veins remote from outermost vein. Ostiolar peritreme (Fig. 16) slightly bent posteriad; carina touching lateral margin of metapleura. Legs slender, densely covered with yellow, long, suberect setae; male fore tibia (Fig. 19) curved inwards at middle, bearing 15 teeth on midventral surface, single small teeth located at apex remote from 
midventral row of teeth; each tibia bearing a number of slender spines.

Abdomen densely covered with yellow, short, reclining setae. Pygophore (Fig. 24) turbinate, nearly symmetrical in dorsal view, posteroventrally covered with two long, stout setae; paramere (Figs 24-26) short, weakly curved, acute toward apex; groove running along paramere broad, entirely visible from dorsal view.

Measurements. [ $0(n=6) / q(n=7)$, holotype in parentheses]. Body length 2.18-2.29/2.21-2.44 (2.25); head length (excl. neck) $0.30-0.32 / 0.30-0.33(0.32)$; head width across eyes $0.36-0.37 / 0.34-0.37$ (0.37); vertex width $0.16-0.17 / 0.17-0.18$ (0.16); width between ocelli 0.09-0.11/0.11-0.12 (0.10); length of antennal segments I-IV: $0.09-0.11 / 0.09-0.11 \quad(0.10)$, $0.32-0.33 / 0.30-0.32 \quad(0.33), \quad 0.27-0.28 / 0.27-0.28 \quad(0.28)$, $0.26-0.29 / 0.26-0.28(0.27)$; length of rostral segments II-IV: 0.09-0.11/0.10-0.11 (0.11), $0.31-0.33 / 0.33-0.34 \quad(0.33)$, $0.20-0.22 / 0.20-0.22 \quad(0.20)$; anterior pronotal width $0.26-0.29 / 0.27-0.30 \quad(0.28)$; mesal pronotal length $0.30-0.31 / 0.30-0.33 \quad(0.31)$; basal pronotal width $0.67-0.72 / 0.69-0.72 \quad(0.72)$; length of embolial margin $0.72-0.75 / 0.71-0.78 \quad(0.72)$; length of cuneal margin $0.33-0.36 / 0.37-0.39(0.36)$; maximum width across hemelytra $0.79-0.82 / 0.81-0.84(0.80)$.

Type material. Holotype ô: (TKPM-IN-12779; Figs 4, 9, 24), labelled "MALAYSIA, Johor, Endau-Rompin, Kampung Peta, 18.v.2005, K. Yamada leg.". Paratypes: 50 (one shown in Figs 14-16, 19, 25, 26), 7\%, same data as holotype. All in TKPM.

Etymology. Named after the type locality, Endau-Rompin, Johor; an adjective.

Distribution. Malaysia (Johor).

Remarks. Amphiareus rompinus sp. n. is most similar in general appearance to $A$. ochraceus and $A$. obscuriceps, but is distinguished from both species by the ostiolar peritreme slightly bent posteriorly (in $A$. ochraceus and A. obscuriceps it is nearly straight and not bent posteriorly); differing from $A$. ochraceus by antennal segment II about 0.9 times as long as width of head across eyes (in $A$. ochraceus, about 1.2 times), the callus demarcated posteriorly by transverse, wide, sinuate depression with dense punctures (vs. demarcated posteriorly by dense punctures and rugula, without depression), and nearly symmetrical pygophore (vs. asymmetrical); differing from $A$. obscuriceps by the uniformly reddish brown head and pronotum (in $A$. obscuriceps, brown to dark brown) and the groove running along paramere entirely visible from dorsal aspect (vs. visible from left posterolateral view).

\section{Amphiareus ruficollaris Yamada \& Hirowatari}

(Figs 5, 10, 20)

Amphiareus ruficollaris Yamada \& Hirowatari, 2003: 298. Holotype: đ̊, Nara, Japan; Osaka Prefecture University.

Diagnosis. Recognized by the blackish brown body (Fig. 5) covered with short dense reclining setae, red to reddish brown postocular region, collar, and callus (Figs 5, 10); antennal segment II as long as head width across eyes, the ante-ocular region about 0.8 times as long as length of eye in dorsal view, and male fore tibia (Fig. 20) nearly straight, bearing 14 teeth on posteroventral surface.

Material examined. $30 \widehat{\delta}, 53 \uparrow$ Vietnam: 10 (Figs 5, 10), Deo Tran Ton, $1950 \mathrm{~m}$ alt., Sapa, Lao Cai, 27.vi.1997, MT (NSMT), 2 + , 23.-25.v.1998, S. Nomura (NSMT); 10, Mt. Phang Si Pang, $1840 \mathrm{~m}$ alt., Lao Cai, 23.v.1998, S. Nomura (NSMT); 1 đ, 2 ㅇ, Deo O Quy Ho, 1750 m alt., Sapa, Lao Cai,

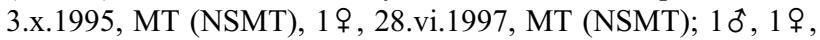
Truong Yen, $900 \mathrm{~m}$ alt., Moc Chau, Son La, 19.-21.vi.1997, MT (NSMT); 30 , Tam Dao, $950 \mathrm{~m}$ alt., Vinh Phuc, 23.ix.1995,

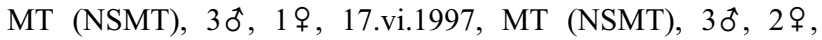
13.vii.1997, MT (NSMT); 1, Tam Dao, 1000 1100 m alt., Vinh Phuc, 3.vii.1997, MT (NSMT), 3 9 , 14.vii.1998, MT (NSMT); 10, Dambri, Bao Loc, Lam Dong, 26.xii.2001, TI (TKPM). Laos: 40ิ, 3 ㅇ, Phu Phan, 16.-18.v.2004, T. Tsuru (TKPM). Thailand: $10,1 \%$, Pakhia, $1500 \mathrm{~m}$ alt., Chiang Dao, Chiang Mai, 4.-6.v.2000, S. Nagashima (TKPM), 50ิ, 19우, 6.-8.v.2002, TI (TKPM); 9 ㅇ, Pang Klang, 1000 1200 m alt., Doi Mae Tho, Chiang Mai, 7.viii.2001, TI (TKPM); 30, 2오, Doi Suthep, 750 850 m alt., Chiang Mai, 5.-20.viii.2001, TI (TKPM); $30^{*}$ (one shown in Fig. 20), 3 $q$, Chiang Khian, 800 900 m alt., Doi Suthep, Chiang Mai, 14.-16.viii.2001, TI (TKPM); 1 ㅇ, Mae Fang N.P., Doi Pha Hom Pok, 1430 m alt., Chiang Mai, 21.xi.2003, M. Földvári (HNHM). Malaysia: 19 , Mt. Berembum, Cameron Highlands, Pahang, 3.iii.2003, S. Nagashima (TKPM); 1 , Mt. Jasar, Cameron Highlands, Pahang, 1.v.2003, S. Nagashima (TKPM).

Distribution. Vietnam*, Laos*, Thailand*, Malaysia*; Japan. This species is recorded from southeastern Asia for the first time.

Remarks. This species is allied to A. obscuriceps, from which it is distinguished by the antennal segment II as long as the head width across eyes (in A. obscuriceps, slightly longer than head width across eyes), the red to reddish brown postocular region, collar and callus (vs. uniformly brown to dark brown), the pronotal posterior margin about 2.6 times as wide as anterior margin (vs. 2.4 times as wide as anterior margin), and the male fore tibia bearing 14 teeth (vs. 18-22 teeth).

ACKNOWLEDGEMENTS. I express special thanks to J.D. Lattin (Oregon State University) for his critical reading of the manuscript and his useful comments. I also thank T. Hirowatari (Osaka Prefecture University, Sakai) for his continuous advice and encouragement, and T. Yasunaga (American Museum of Natural History, New York) and M. Tomokuni (NSMT) for valuable advice and critical comments on my study. I am indebted to the following entomologists for the loan or donation of materials, and/or kind assistance in the field: M. Tomokuni (NSMT), R. Hashim (University of Malaya, Kuala Lumpur), Y. Nakatani (National Institute for Agro-Environmental Sciences, Tsukuba), B.W. Lee (Korea National Arboretum, Gyeonggi-do), T. Ishikawa (Tokyo University of Agriculture, Atsugi), D. Rédei (HNHM), and S. Nagashima (Itami City Museum of Insect, Itami). This study was partly supported by Grant-in-Aid for Young Scientists (B) from the Japan Ministry of Education, Culture, Sports, Science and Technology (No. 20780043).

\section{REFERENCES}

Distant W.L. 1904: Rhynchotal notes. XXV. Heteroptera. Fam. Anthocoridae. Ann. Mag. Nat. Hist. 7: 219-222.

Distant W.L. 1906: Order Rhynchota. Suborder Heteroptera. Family Anthocoridae. In Bingham C.T. (ed.): The Fauna of 
British India Including Ceylon and Burma. Vol. 3. Tayler and Francis, London, pp. 1-10.

Distant W.L. 1910: Order Rhynchota. Suborder Heteroptera. Family Anthocoridae. In Bingham C.T. (ed.): The Fauna of British India Including Ceylon and Burma. Vol. 5. Tayler and Francis, London, pp. 295-309.

Henry T.J., Wheeler A.G. JR. \& Steiner W.E. JR. 2008: First North American records of Amphiareus obscuriceps (Poppius) (Hemiptera: Heteroptera: Anthocoridae), with a discussion of dead-leaf microhabitats. Proc. Entomol. Soc. Wash. 110: 402-416.

Herring J.L. 1965: The states of Amphiareus Distant, Buchananiella Reuter, Poronotellus Kirkaldy (Hemiptera: Anthocoridae). Proc. Entomol. Soc. Wash. 67: 202-203.

KIRKALDY G.W. 1904: Bibliographical and nomenclatorial notes on the Hemiptera. No. 3. Entomologist 37: 279-283.

KIRKALDY G.W. 1906: List of the genera of the Pagiopodous Hemiptera-Heteroptera with their type-species, from 1758 to 1904 (and also of the aquatic and semi-aquatic Trochalopoda). Trans. Am. Entomol. Soc. 32: 117-156.

LATTIN J.D. 1999: Dead leaf clusters as habitat for adult Calliodis temnostethoides and Cardiastethus luridellus and other anthocorids (Hemiptera: Heteroptera: Anthocoridae). Great Lakes Entomol. 32: 33-38.

Mockford E.L. 1993: North American Psocoptera (Insecta). Sandhill Crane Press, Florida, 455 pp.

NAKATANI Y. 2004: Heteroptera. In Hayashi T., Nakamura S., Visarathanonth P. et al. (eds): Stored Rice Insect Pests and their Natural Enemies in Thailand. JIRCAS International Agricultural Series No. 13. Funny Publishing, Bangkok, pp. 31-39.

PéricARt J. 1996: Family Anthocoridae Fieber, 1836 - Flower bugs, minute pirate bugs. In Aukema B. \& Rieger C. (eds): Catalogue of the Heteroptera of the Palaearctic Region. Vol. 2. Cimicomorpha I. The Netherlands Entomological Society, Amsterdam, pp. 108-140, xi-xii.

Poppius B. 1909: Beiträge zur Kenntnis der Anthocoriden. Acta Soc. Sci. Fenn. 37: 1-43.

Reuter O.M. 1971: Acanthiidae americanae descriptae. Öfv. Kungl. Vet. Ak. Förh. 28: 557-568.

Yamada K. \& Hirowatari T. 2003: Japanese species of the genus Amphiareus Distant (Heteroptera: Anthocoridae), with descriptions of two new species. Entomol. Sci. 6: 289-300.

Received May 16, 2008; revised and accepted July 24, 2008 